\title{
The third wave in health sciences education
}

\author{
Geoff Norman
}

Published online: 18 July 2013

(c) Springer Science+Business Media Dordrecht 2013

In 1980, the futurist, Alvin Toffler, published a book, The Third Wave, in which he described human history in terms of 3 waves; the first related to agriculture and accumulation of land mass, with lords and ladies owning vast tracts of land to be farmed by their serfs, the second, the industrial revolution, related to the accumulation of wealth through the efficient production of mass goods, leading to an aristocracy based on finance and resources - the Carnegies, Rockefellers, and Vanderbilts of late nineteenth century America, and, in 1971 still far in the future but now upon us, a third wave based on knowledge. Of course, the computer revolution, and the instant access to the world's knowledge through Google, exemplifies the third wave.

To write this editorial, I perused the table of contents of the next few issues, and discovered something I was only dimly aware of. We are seeing more and more papers related to the "science of learning" in the words of Richard Mayer, experimental research based on cognitive theories of the nature of human learning. Seven of the next 20 papers in the AHSE publication queue are in this tradition. In addition, many of the researchers who have developed this paradigm within mainstream psychology are now publishing a number of papers in health sciences-more on this later. We appear to be experiencing a parallel three wave evolution. I am not referring to the personae-that was covered in an article I wrote a few years ago (Norman 2011). Rather, I see a quiet, but dramatic shift occurring in the research paradigms we employ.

The first was dominant when I entered the field. Its roots were in behaviorism, which specifically excluded mental processes from its purview. This ascetic paradigm reduced the world of learning to reinforcement of simple responses to simple stimuli. We created long lists of behavioral objectives, which implicitly reduced the graduating physician to an interminable checklist of behaviours (the resemblance to Competency Based Education is, I'm sure, just coincidental). We tested competence with multiple choice questions, with one right answer (some things don't change) and "Patient Management Problems", where once again, the dialog between physician and patient was reduced to a long list of items to

G. Norman $(\bowtie)$

McMaster University, Hamilton, ON, Canada

e-mail: norman@mcmaster.ca 
be endorsed or ignored. Our students may well have felt like Pavlovian dogs, salivating on command.

Perhaps not surprisingly, such an approach did not go down well in the changing times of the last quarter of the twentieth century. Soon a noisy (though not bloody) revolution occurred, as qualitative research methods, adapted from sociology, came to dominate meetings like the American Educational Research Association and many journals. Among a number of tenets of the new field was an explicit interest in the goals, motivations and insights of the participants (and it is likely not coincidental that, with the ascendancy of the new paradigm, "subject", signifying passive acceptance of the researcher's instructions, was changed to "participant" a term signifying equality and mutual benefit, which likely was rarely achieved). The raw data for the research was the words they spoke, not the numbers extracted off a piece of paper. There was an explicit assumption that people had insight into the reasons why they did what they did, and could express these insights.

The qualitative-quantitative wars went on for far longer than one might have anticipated-about 3 decades, and it is not clear that the war is over. More likely, as in Korea, we have achieved an armistice, not a peace. Most journals now publish sizeable numbers of both qualitative and quantitative studies. One study we did of submissions to AHSE showed that between 2005 and 2008, $23 \%$ of accepted manuscripts in AHSE were qualitative, and the chance of acceptance was $43 \%$, only slightly behind psychometric studies, at $45 \%$. But they remain two solitudes, with different practitioners and different canons. Lip service is paid to "mixed methods" but this usually reduces to an interview followed by a survey, which does a disservice to both research traditions.

In light of the third wave to be described, it is worth reiterating that, while the two traditions differ in many assumptions, one critical distinction is that qualitative methods rely almost exclusively in verbal reports from participants. The words uttered by the people in our studies are viewed as windows on their minds-explicit avenues to access the goals, motivations, and actions of the participants. Conversely, it appears that the quantitative tradition rarely goes beyond the scores, ratings or other outcomes to pursue "why" questions.

And there we sat around 2010 or so. But in the past few years, the third wave has begun breaking on our shores, with little fanfare, and certainly no bloodshed. I first became aware of it when I began to see some of my heroes from cognitive psychology appearing in our journals. Richard Mayer, chair of psychology at UC Santa Barbara, one of the champions of cognitive load theory, has published in Medical Education (Mayer 2010; Issa et al. 2011). Henry Roediger, former editor of Journal of Experimental Psychology: Learning, Memory and Cognition, published a review article in Medical Education (Larsen et al. 2008, 2009) and has an article in this issue of AHSE (Larsen et al. 2013). Robert Bjork, former editor of Psychological Review, has published a paper in Journal of General Internal Medicine (Bell et al. 2008). Jeroen van Merriënboer, another major theoretician in cognitive load theory (van Merriënboer and Sweller 2010), is now on faculty at the University of Maastricht and has contributed articles to Medical Education (Sibbald et al. 2013b; van Merriënboer and Sweller 2010), Medical Teacher, (Tjiam et al. 2012) and AHSE (Sibbald et al. 2013a). And there are others who are crossing the divide-Wolfgang Gaissmeier and Fred Paas come to mind.

Who are these people and why are they here? All bring a strong grounding in cognitive psychology, which includes both theories based on well established aspects of human learning and memory, and controlled experimental procedures. One clear distinction between the axioms of the cognitive wave and the second wave is that, although both are clearly interested in thinking and learning, for the qualitative researcher, verbal reports are 
the data. The cognitive researchers are much more circumspect, and begin with the assumption that we are basically unaware of the mechanisms that guide our actions (Bargh and Chartrand 1999). This perspective is pervasive. As some examples, cognitive load theory is based on the very small capacity of working memory, and has large consequences for instruction. But while it is easy to measure the size of WM, it would be nonsense to ask a participant whether she felt her WM was near its limit in a given task. Dual process theory, which recently has emerged as the most popular contemporary theory of clinical reasoning, explicitly acknowledges that System 1 is "unconscious and automatic", hence not available for introspection. The literature on "heuristics and biases" which has been used frequently as an explanation for diagnostic errors, again presumes that these heuristics are largely unconscious, and that we are largely unaware of when the heuristics can lead us astray.

Thus, the third wave is fundamentally distinct. Instead of theory-free inquiry, which distinguished the first wave, and theory-generating inquiry, which characterizes much of qualitative research, the cognitive wave is almost entirely theory-testing. Instead of reliance on verbal reports, the third wave views them with little credibility and devises other measures of psychological attributes. Finally, there is a third critical distinction. When such theory-based interventions are incorporated into instruction, the effects can be dramatic. Instead of the almost uniform finding that approaches like simulation (Zendejas et al. 2013) or internet-based learning (Cook et al. 2008)have an effect size of 1 against nothing and 0 against anything, the effects of these interventions appear large and consistent (Mayer 2010).

It is unlikely any of these paradigms will disappear. All make a contribution to understanding of the nature of learning, ultimately to the betterment of teaching. And all ultimately enrich the field. Many years ago, Lee Shulman wrote about disciplines of inquiry in education. It appears we have one more to add to the list.

\section{References}

Bargh, J. A., \& Chartrand, T. L. (1999). The unbearable automaticity of being. American Psychologist, 54(7), 462.

Bell, D. S., Harless, C. E., Higa, J. K., Bjork, E. L., Bjork, R. A., Bazargan, M., et al. (2008). Knowledge retention after an online tutorial: A randomized educational experiment among resident physicians. Journal of General Internal Medicine, 23(8), 1164-1171.

Cook, D. A., Levinson, A. J., Garside, S., Dupras, D. M., Erwin, P. J., \& Montori, V. M. (2008). Internetbased learning in the health professions. JAMA, the Journal of the American Medical Association, 300(10), 1181-1196.

Issa, N., Schuller, M., Santacaterina, S., Shapiro, M., Wang, E., Mayer, R. E., et al. (2011). Applying multimedia design principles enhances learning in medical education. Medical Education, 45(8), 818-826.

Larsen, D. P., Butler, A. C., \& Roediger, H. L., I. I. I. (2008). Test-enhanced learning in medical education. Medical Education, 42(10), 959-966.

Larsen, D. P., Butler, A. C., \& Roediger, H. L., I. I. I. (2009). Repeated testing improves long-term retention relative to repeated study: A randomised controlled trial. Medical Education, 43(12), 1174-1181.

Larsen, D. P., Butler, A. C., Lawson, A. L., \& Roediger III, H. L. (2013). The importance of seeing the patient: Test-enhanced learning with standardized patients and written tests improves clinical application of knowledge. Advances in Health Sciences Education, 18(4), 1-17.

Mayer, R. E. (2010). Applying the science of learning to medical education. Medical Education, 44(6), 543-549.

Norman, G. (2011). Fifty years of medical education research: Waves of migration.Medical Education, 45(8), 785-791. 
Sibbald, M., De Bruin, A. B., \& van Merrienboer, J. J. (2013a). Finding and fixing mistakes: Do checklists work for clinicians with different levels of experience? Advances in Health Sciences Education, 18(1), $1-9$.

Sibbald, M., de Bruin, A. B., \& van Merrienboer, J. J. (2013b). Checklists improve experts' diagnostic decisions. Medical Education, 47(3), 301-308.

Tjiam, I. M., Schout, B. M., Hendrikx, A. J., Scherpbier, A. J., Witjes, J. A., \& Van Merriënboer, J. J. (2012). Designing simulator-based training: An approach integrating cognitive task analysis and fourcomponent instructional design. Medical Teacher, 34(10), e698-e707.

Toffler, A. (1980). The third wave. New York, NY: Babntam.

van Merriënboer, J. J., \& Sweller, J. (2010). Cognitive load theory in health professional education: Design principles and strategies. Medical Education, 44(1), 85-93.

Zendejas, B., Brydges, R., Hamstra, S. J., \& Cook, D. A. (2013). State of the evidence on simulation-based training for laparoscopic surgery: A systematic review. Annals of Surgery, 257(4), 586-593. 